$$
\begin{aligned}
& \text {-----مجلة علوم الر افدين، المجلد 27، العدد 1، ص } 64 \text {-75، 2018------ } \\
& \text { تنقية مياه الصرف الصحي بالتعريض المباشر للأثعة الثمسية } \\
& \text { ريم أياد طلعت } \\
& \text { *عبد العزيز يونس طليع الصفاوي } \\
& \text { قسم علوم البيئة/ كلية البيئة وتقاناتها/ جامعة الموصل }
\end{aligned}
$$

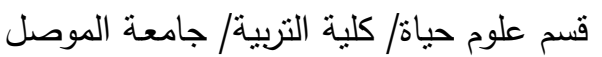

$$
\begin{aligned}
& \text { * Email: Sagffewi@yahoo.com }
\end{aligned}
$$

$$
\text { (أستلم 2013/11/20 ؛ قُبل 24/2/ }
$$

\begin{abstract}
الملخص
تضمنت الدراسة إجراء معالجة لمياه الصرف الصحي بتعريض المباه للأشعة الثمسية بعد وضعها بأحواض بلاستيكية

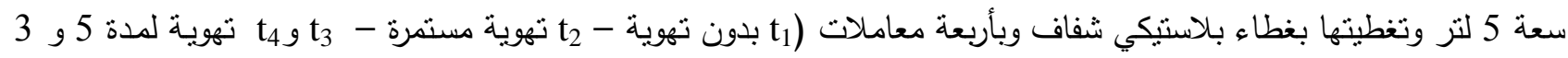



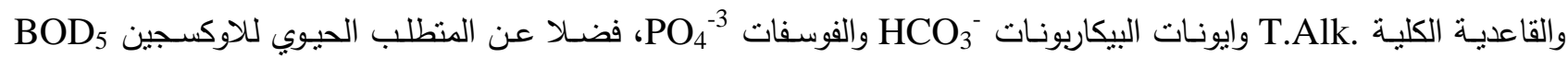
وقياس كل من العدد الكلي للبكتريا TPC وبكتريا القولون البرازية F. coliform وبكتريا E. coli وفقا للطرائق المعتمدة عالميا، لمعرفة التغيرات النوعية التي تحدث للمياه الملوثة خلال مدة التعريض للأشعة الثمسية.

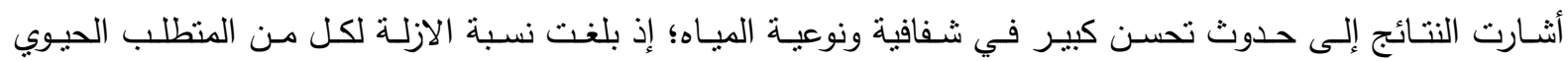

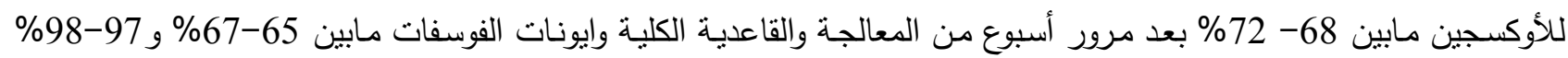
على التوالي في نهاية المعالجة، كذلك حدوث انخفاض واضح في أعداد البكتريا المدروسة أثناء المعالجة لتبلغ نسبة الإزالة 99 \% للعدد الكلي للبكتريا و 100 \% لكل من بكتريا القولون البرازية وبكتريا E.coli بعد مرور أربعة أيام من المعالجة. الكلمات الدالة: الأشعة الثمسية لمعالجة مياه المجاري، المعالجة الفيزياوية لمياه المجاري.
\end{abstract}

\title{
Sewage Water Purification Through Direct Exposure to Solar Radiation
}

\author{
Abdul-Aziz Y. Al-Saffawi \\ Department of Biology/College of Education/ \\ University of Mosul
}

\section{ABSTRACT}

Reem A. Talaat

Department of Environ. Sciencel

College of Environment \& Technology/

University of Mosul

The study deals with ecofriendly treatment of sewage water by direct exposure to solar radiation, The water was put in 5 liter plastic containers covered with transparent covers, the experiments were conducted with four treatments [ $t_{1}$ : with out aeration, $t_{2}$ : continuous aeration, $t_{3}$ and $t_{4}$ : with 5,3 hour aeration daily] respectively, in order to investigate the quality variation of the polluted water, periodical measurements of the parameters: Salinity, pH, T. Hardness, T. Alkalinity, $\mathrm{HCO}_{3}{ }^{-}$ions, $\mathrm{PO}_{4}{ }^{-3}$ ions, $\mathrm{BOD}_{5}$, total count of bacteria, E. coli and faecal coliform bacteria according to international standard methods.

The results showed that after treatment occurred with significant improvement in transparency and water quality, removal percentage of $\mathrm{BOD}_{5} 68-72 \%$ after one week of treatment, T. alk. and $\mathrm{PO}_{4}^{-3} 65-67 \%$ and $95-97 \%$ respectively in the end of the treatment. Also, high decreasing percent in number of TPC 99\%, F. coliform and E. coli 100\% after four days of treatment.

Keywords: solar treatment of sewage water, physical treatment of sewage water. 


\section{المقدمة}

أضحت قضية البيئة وحمايتها من التلوث من أكثر القضايا حساسية في عالم اليوم، واستوجب التعامل معها بأكبر قدر ممكن من الجدية واحتلت مكانة مرموقة في سلم عناية المجتمع الدولي، لأن هذه القضية ترتبط بيقاء الإنسان وصحته وتقدمهـ



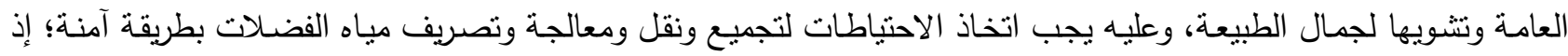
يستخدم البشر في كثير من أجزاء العالم وحتى الوقت الحاضر مياه شرب ملوثة بسبب التجاوزات والسلوكيات الخاطئة للمواطنين في التعامل مع الموارد المائية مما يسبب مشاكل صحية خطيرة وبخاصة الدول النامية التي تواجه مشاكل صحية بسبب تصريف مهاه مياه المجاري الى الموارد المائية إما بدون معاملة أو بمعاملة غير كفوءة (الصفاوي والسردار ، 2013).


التنقية الذاتية Self Purification (Ifabiyi, 2008). والتي تتضمن عدة عمليات فيزيائية وكيميائية وحيوية تؤدي الى تتقية المياه؛ اذ ينت تخفيف وانتتـار الملوثات في المورد المائي كذللك امتزاز الملوثات من قبل المواد العالقة والتي تترسب إلى القاع، فضـلاً عن عمليات الفلترة التي تقوم بها اللافقاريات ذات التغذية الترشيحية، كذللك امتصاص الملوثات من قبل النباتات الراقية فضـلاً عن التفاعلات الكيموضوئية التي تحفز بوساطة الإثعاع الثمسي (Ostroumov, 2006)، فالإشعاع الثمسي المتمثل بالأشـعة فوق البنفسجية UV والأشتعة تحت الحمراء والأشـعة الحمراء تعمل على القضـاء على المسببات المرضية مـن خـلال ميكانيكيات مختلفة منها:

- امتصاص الأشعة nd 400-320) UV-A من قبل الـ DNA مسببة تكوين thymine dimers الذي يؤدي إلى عرقلة تضاعف الـ DNA فضلاً عن حدوث الطفرات نتيجة لعمليات الإصلاح الخاطئة. 2 - امنصاص أثنعة الـ UV من قبل المركبات العضوية يحفزحدوث التفاعلات الكيموضوئية مؤدية إلى تكوين مجاميع اوكسجينية فعالة ROS التي يمكنها ألحاق الضرر بالكائنات الدقيقة عن طريق أكسدة المكونات الخلوية (Oates et al., 2003). 3- توليد حرارة في الماء نتيجة لامتصاص الأشعة الحمراء وتحت الحمراء والتي تسبب مسخ البروتين ومن ثم أعاقة وظيفته وقد نسبب الموت للكائن الحي (Brock et al., 2002). أن الأحياء المجهرية المرضية الني تصيب الإنسان تكون متكيفة للمعيشة في أمعاء الإنسان لكن حال انتقالها إلى البيئة ستكون حساسة جداً للظروف القاسية خارج جسم الإنسان؛ إذ ليس بمقدورها مقاومة ارتفاع درجات الحرارة ولاتمتلك ميكانيكيات لمقاومة أشعة UV مما قد يودي الى قتل الأحياء المجهرية المرضية (Schertenleib and Wegelin, 2002). تشير الدراسة التي قام بها Vidali (2000) لدور الإشعاع الثمسي في تطهير المياه الملوثة إلى نجاح المعاملة بضوء الثمس في القضاء على بكتريا الـ Enterococcus faecalis وأكد على ألى أمكانية استخدام هذه الطريقة في البلدان التي تتميز بطول فترة الإثتعاع الثمسي كالدول الواقعة في المناطق الجافة وشبه الجافة. وهذا ماأكدته منظمة الصحة العالمية

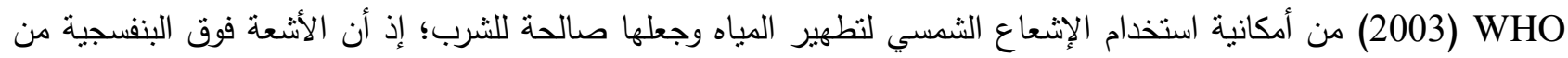

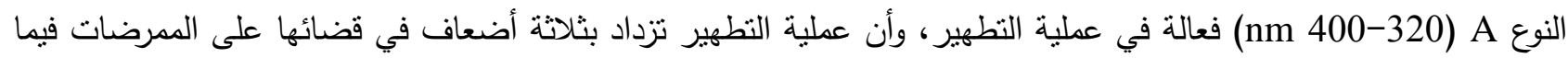
إذا كانت درجة حرارة الماء مرتفعة نسبياً، لذلك جاءت هذه الدراسة لمعرفة إمكانية معالجة مياه المجاري بالتعريض للأشعة الثمسية 
أخذت مياه المجاري بواقع 5 لتر ووضعت بأحواض بلاسنيكية ابعادها ( 30، 21، 10 سم) وغطيت بغطاء بلاستيكي شفاف

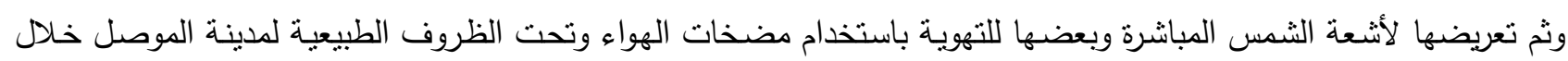
شهر ايلول وقد تم تكرار هذه التجربة مرنين وكانت المعاملات كالأتي:

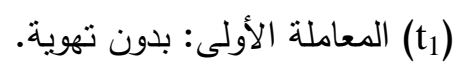

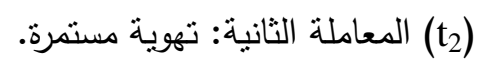

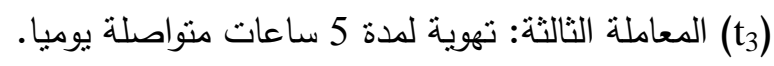
(المعاملة الرابعة: تهوية لمدة 3 ساعات منواصلة يوميا.

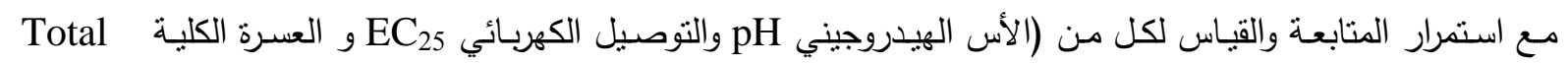

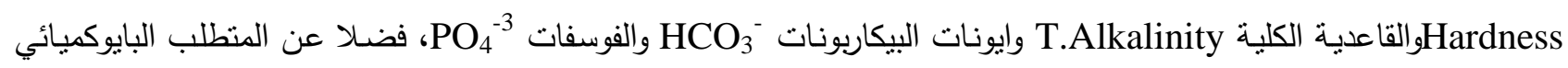
للاوكسجين BOD وقياس كل من العدد الكلي للبكتريا Total Plate Count وبكتريا القولون البرازية coliform وبكتريا E.coli وفقا للطرائق المعتمدة عالميا (Kumar et al., 2011 APHA, 1998)، لمعرفة التغيرات النوعية التي تحدث للمياه الملوثة خلال مدة التعريض للأشعة الثمسية.

\section{النتائج والمناقشة}

توصف التتقيـة الذاتيـة الطبيعيـة Self-purification بأنها ملخص لجميع العمليـات الفيزيائيـة والكيميائية والبايولوجيـة ودور الاثتعة الثمسية التي من خلالها ستعمل على خفض كمية الملوثات، مثل عمليات التحلل البايولوجي والنترجة والتعدين واستيعاب المواد العضوية الذائبة والمغذيات الموجودة في المباه بوساطة الكائنات الحية كالبكتريا والفطريات واللافقاريات والطحالب البعل

.(Maalah, 2013 ؛ Heidenwag et al., 2001)

تشير نتائج الدارسة الى حدوث تحسن كبير في شفافية الماء كما موضح بالصورة (1) مـع اختفاء الروائح الكريهة، وقد يعزى ذلك الى وجود الطحالب في الماء التي تعمل على تحسين تهوية المياه للمعاملة th فضلا عن عملية التهوية لبقية المعاملات وبالتالي خلق ظروف هوائية Aerobic condition وتغيير مسارات التفاعلات الحيوية وتكوين نواتـج غير ضارة للنظام البيئي المائي او قد تكون بسبب تاثير الاشعة الثمسية في تتشيط التفاعلات الكيموضوئية خاصـة عند وجود بعض المركبات العضوية

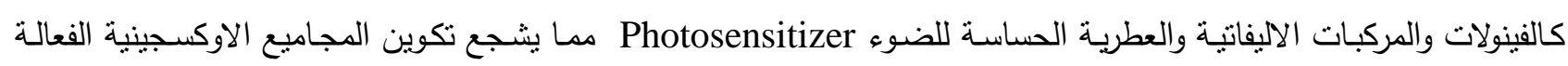
Hussein and )

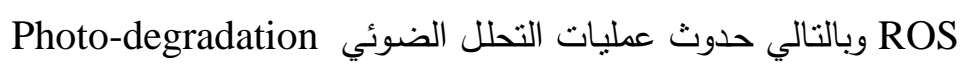
Abass, 2010 ؛ McGuigana et al., 2012 ؛ وهذه العمليات ستؤدي الى تحسين شفافية المياه، وهذا ما أكده (الصفاوي والسنجري، 2013) عند دراستهها لعمليات التتقية الذاتية لمياه مجاري وادي الخرازي في مدينة الموصل؛ اذ أنشارا إلى دور التنقية

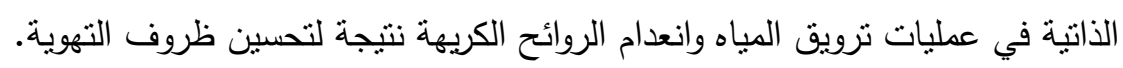
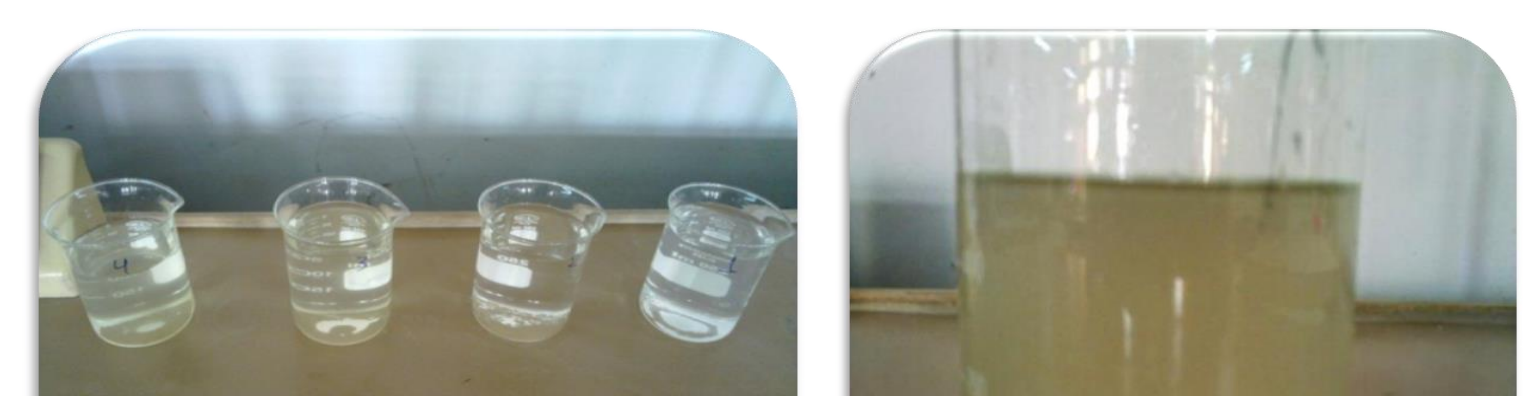


\section{الصورة 1: مياه المجاري قبل ويعد المعالجة الطبيعية}

أمسا قيم الأس الهيدروجيني والموضحة في الجدول (1) فيلحظ أنها نأخذ بالارتفاع لتصل الى (10.63) بعد مرور (4)

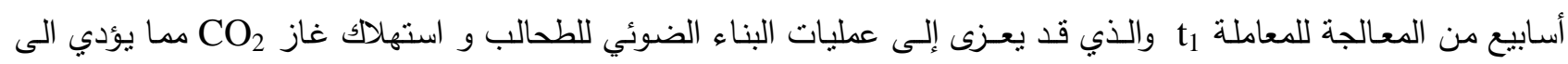
زيادة تكوين المسببات القاعدية وإطلاقها الى البيئة المائية وهذا ماكده كل من (ألثـاهري وآخرون، 2009؛ الصفاوي والسردار، 2013) كما في المعادلات الآتية :

$2 \mathrm{HCO}_{3}^{-} \rightarrow \mathrm{CO}_{3}{ }^{-}+\mathrm{CO}_{2}+\mathrm{H}_{2} \mathrm{O}$
$\mathrm{CO}_{3}{ }^{=}+\mathrm{H}_{2} \mathrm{O} \rightarrow \mathrm{CO}_{2}+2 \mathrm{OH}^{-}$

الجدول 1: معدل نتائج الدالة الحامضية خلال مدة المعالجة الطبيعية

\begin{tabular}{|c|c|c|c|c|c|c|}
\hline بعد أريعة أسابيع & بع ثلاثة أسابيع & بعد أسبوع من & بعد أريعة أيام من & بعد يوم من & قالجة & المعاملات \\
\hline 10.63 & 10.44 & 8.28 & 8.02 & 8.16 & 7.67 & $\mathrm{t}_{1}$ \\
\hline 8.52 & 8.55 & 8.65 & 8.64 & 8.71 & & $t_{2}$ \\
\hline 9.20 & 9.22 & 8.68 & 8.37 & 8.41 & & $\mathrm{t}_{3}$ \\
\hline 9.39 & 9.26 & 8.58 & 8.30 & 8.32 & & $t_{4}$ \\
\hline
\end{tabular}

بينما كانت القيم اقل من ذلك في بقية المعاملات وقد يعزى ذلك الى دور عملية التهوية ودخول الاوكسجين الذائب في سلسلة من التفاعلات الضوئية لتكوين الجذور الحرة Free radicals واحتمال تفاعل ايونات الهيدروكسيل OH لتكوين الماء، كذلك يلاحظ من الجدول (2) تذبذب قيم التوصيل الكهربائي فالارتفاع في القيم قد يعود الى عمليات التحلل للمواد العضوية والتفاعلات التي تحدث في المياه والتي تؤدي الى إذابـة بعض المركبات الموجودة فيه (الصفاوي وآخرون،2009؛ كما في المعادلات الآتية : (Manahan,2004

$\left\{\mathrm{CH}_{2} \mathrm{O}\right\}+\mathrm{O}_{2} \stackrel{\text { Microorganisms }}{\longrightarrow} \mathrm{CO}_{2}+\mathrm{H}_{2} \mathrm{O}$

$\mathrm{H}_{2} \mathrm{CO}_{3}+\mathrm{CaCO} \longrightarrow \mathrm{Ca}\left(\mathrm{HCO}_{3}\right)_{2}$ 


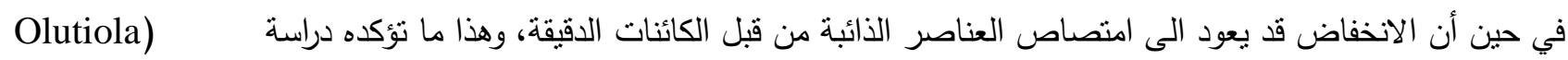

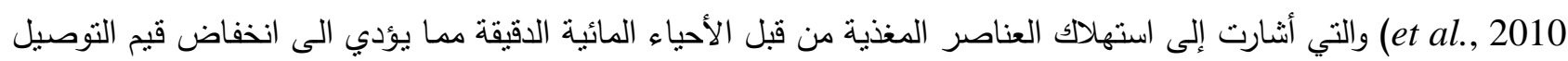
الكهربائي، فضلا عن حدوث عمليات الترسيب التي تسهم في هذا الانخفاض (Ostroumov, 2006).

الجدول 2: معدل نتائج التوصيلية الكهريائية بوحدة (uS/cm) خلال مدة المعالجة الطبيعية

\begin{tabular}{|c|c|c|c|c|c|c|}
\hline بع أريعة أسابيع & أسبابيع من & بعد أسبوع من & من المعالجة أريعة أيام & بعد يوم من & المعالجة & المعاملات \\
\hline 691 & 818 & 720 & 840 & 701 & 761 & $t_{1}$ \\
\hline 720 & 858 & 733 & 811 & 688 & & $t_{2}$ \\
\hline 748 & 885 & 733 & 840 & 688 & & $t_{3}$ \\
\hline 762 & 939 & 746 & 840 & 688 & & $\mathrm{t}_{4}$ \\
\hline
\end{tabular}

أما بالنسبة للنلوث العضوي فان استمرار طرح مياه المجاري مباشرة إلى النهر دون أي معاملة تذكر سيؤدي إلى التأثنير

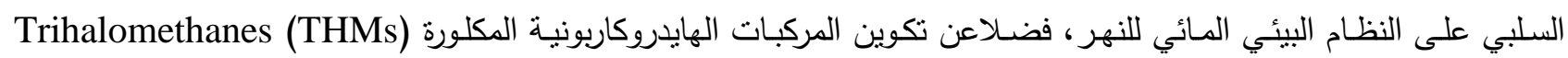

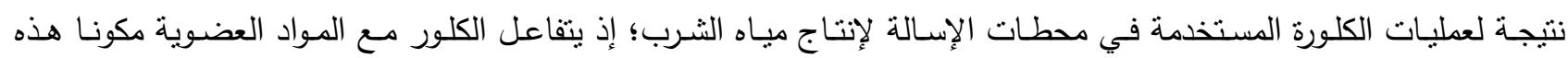
المركبات التي تعد احد أسباب سرطان الكلى والمثانة والقولون والمستقيم (Lou et al., 2010). ويشير الجدول (3) إلى ان معدل إنى

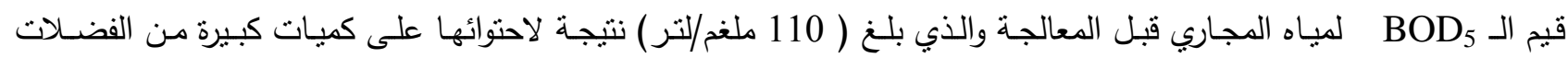
العضوية مما ينعكس سلبا على تركيز Do ثم حدوث عمليات التحلل اللاهوائي وتكوين نواتج ضـارة بالبيئة المائية مـع انبعاث الروائح الكريهة والمزعجة (الصفاوي والطائي، 2013؛الصفاوي و السنجري، 2013) كما في المعادلات التالية: $4 \mathrm{CH}_{3} \mathrm{H}_{7} \mathrm{O}_{2} \mathrm{NS}+8 \mathrm{H}_{2} \mathrm{O} \longrightarrow 4 \mathrm{CH}_{3} \mathrm{COOH}+4 \mathrm{NH}_{3}+4 \mathrm{H}_{2} \mathrm{~S}$ $4 \mathrm{CH}_{3} \mathrm{COOH}+8 \mathrm{H} \longrightarrow 5 \mathrm{CH}_{4}+3 \mathrm{CO}_{2}+2 \mathrm{H}_{2} \mathrm{O}$

الجدول 3: معدل نتائج BOD5 (ملفم/لتر) خلال مدة المعالجة الطبيعية

\begin{tabular}{|c|c|c|c|c|c|c|c|}
\hline الإزالة \% & أسابيع من أربعة & أسابيع من ثلاثة & بعد أسبوع من & أيام من أربعة & بعد يوم من & قالجبل & المعاملات \\
\hline$\% 63$ & 40.5 & 41.4 & 31.7 & - & 52.8 & 110 & $t_{1}$ \\
\hline$\% 78$ & 23.8 & 31.2 & 34.3 & - & 88.0 & & $t_{2}$ \\
\hline$\% 70$ & 32.6 & 44.9 & 35.2 & - & 88.0 & & $t_{3}$ \\
\hline$\% 72$ & 29.9 & 38.7 & 30.8 & - & 88.0 & & $\mathrm{t}_{4}$ \\
\hline
\end{tabular}


وقد حدث انخفاض نسبي لتركيز الـ BOD حيث بلغت نسبة الإزالة بعد يوم واحد من التعريض لأشعة الثمس إلى (52 ،

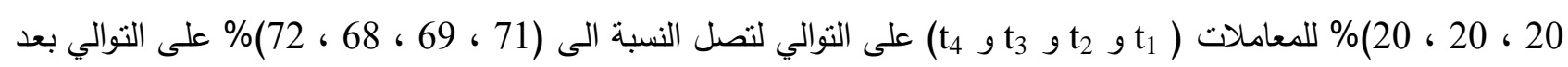
مرور أسبوع من المعالجة مقارنة بتركيز الـ BOD قبل المعالجة. ويعود هذا الانخفاض في التركيز الى تأثنير الأشعة الثنسية

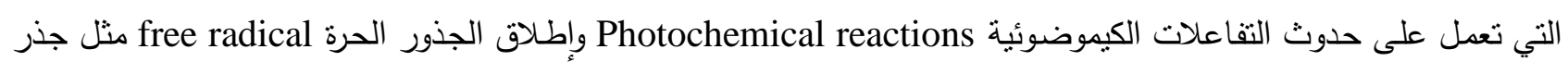
الهيدروكسيل الحر (OH) التي تهاجم وتتفاعل مع المواد العضوية (Nogueira et al., 2008)، وكذللك الى عمليات التحلل من

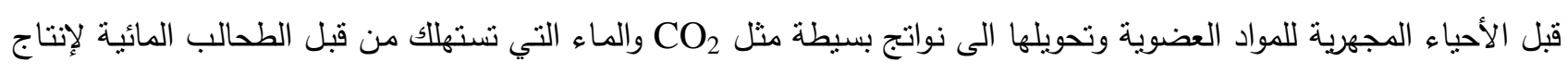
المواد العضوية اللازمة لبناء الخلايا الجديدة وبدورها تقوم بتجهيز الماء بالأوكسجين الذائب الذي يستغل من قبل الأحياء الدقيقة لعمليات التحلل للمواد العضوية (الصفاوي والعساف، 2013) وكل هذه العطليات سنؤدي الى خفض تركيز الـ وهذا ما لاحظه (Nogueira et al., 2008) في دراسته لتأثثر التعريض لأشعة الثمس في معالجة المياه الملوثة، حيث بلغت نسبة الإزالة للحمل العضوي (90)\% بعد مرور عدة ساعات من التعريض.

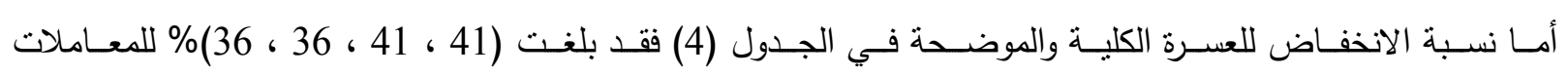

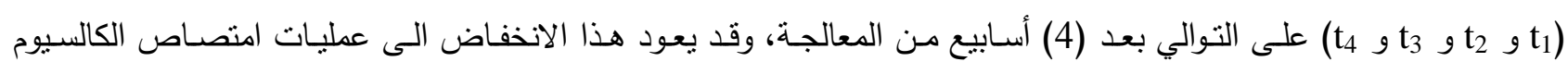
والمغنسيوم اللازم للنشاطات الحيوية للأحياء المائية آو بسبب وجود مجاميع الكبريتات والسلفاهايدرايل في المواد الكاربوهيدراتيـة

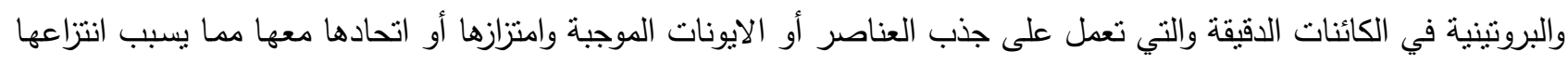

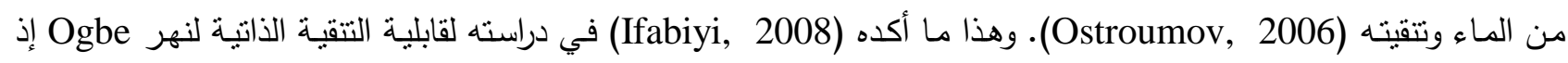
انخفضت العسرة الكلية بنسبة (30)\% بعد قطع مسافة (25) كم.

الجدول 4: معدل نتائج العسرة الكلية (ملفم/تتر. على اساس CaCO3) خلال مدة المعالجة الطبيعية

\begin{tabular}{|c|c|c|c|c|c|c|c|}
\hline الإزالةة & أسابيع من أربعة & أسابيع من ثلاثة & بعد أسبوع من & بعد أربعة أيام & بع يوم من & قالمعلة & المعاملات \\
\hline$\% 41$ & 204 & 248 & 284 & 288 & 358 & 346 & $\mathrm{t}_{1}$ \\
\hline$\% 41$ & 202 & 260 & 284 & 292 & 338 & & $t_{2}$ \\
\hline$\% 36$ & 220 & 272 & 290 & 292 & 346 & & $t_{3}$ \\
\hline$\% 36$ & 218 & 286 & 258 & 296 & 340 & & $t_{4}$ \\
\hline
\end{tabular}

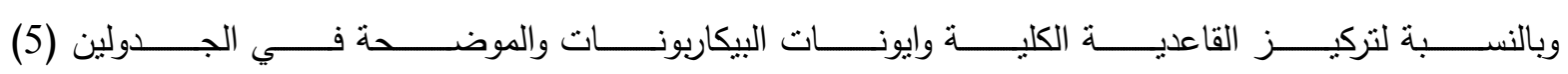
و (6) على النوالي فنتير النتائج بان نسبة الإزالة لكل منهما بلغت (66، 67، 65، 67) وائز 
الجدول 5: معدل نتائج ايونات البيكاريونات (ملفم/تتر) خلال مدة المعالجة الطبيعية

\begin{tabular}{|c|c|c|c|c|c|c|c|}
\hline الإزالةة & أسابيع من أربعة & أسابيع من ثلاثة & من المعالجة أسبوع & من المعالجة أريعة أيام & بعد يوم من & قالمعالجة & المعاملات \\
\hline$\% 66$ & 85 & 120 & 237 & 232 & 239 & 251 & $\mathrm{t}_{1}$ \\
\hline$\% 67$ & 81 & 112 & 239 & 234 & 237 & & $t_{2}$ \\
\hline$\% 65$ & 88 & 112 & 239 & 232 & 239 & & $t_{3}$ \\
\hline$\% 67$ & 81 & 115 & 239 & 237 & 242 & & $t_{4}$ \\
\hline
\end{tabular}

الجدول 6: معدل نتائج القاعدية الكلية (ملفم/تتر. على اساس CaCO3) خلال مدة المعالجة الطبيعية

\begin{tabular}{|c|c|c|c|c|c|c|c|}
\hline الإزالةة\% & أسابيع من أريعة & بعد ثلاثة أسابيع & بعد أسبوع من & بعد الريعة أيام & بعد يوم من & المعالجة & المعاملات \\
\hline$\% 66$ & 70 & 98 & 194 & 190 & 196 & 206 & $\mathrm{t}_{1}$ \\
\hline$\% 67$ & 66 & 92 & 196 & 192 & 194 & & $t_{2}$ \\
\hline$\% 65$ & 72 & 92 & 196 & 190 & 196 & & $t_{3}$ \\
\hline$\% 67$ & 66 & 94 & 196 & 194 & 198 & & $t_{4}$ \\
\hline
\end{tabular}

للمعاملات

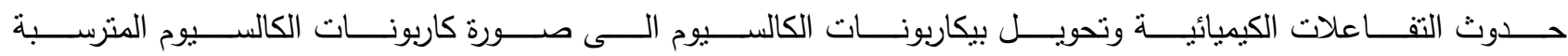

.(Manahan, 2004)

أما معدل نتائج ايونات الفوسفات والموضحة في الجدول (7) فقد أظهرت النتائج حدوث انخفاض كبير في تراكيزها؛ إذ بلغت

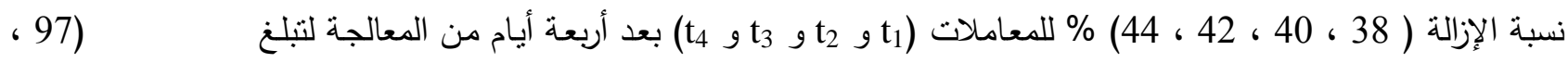
98 ، 98 ، 98 )\% على التوالي بعد (4) أسابيع من التعريض لأشعة الثمس، وقد يعود هذا الانخفاض الى حدوث التقاعلات

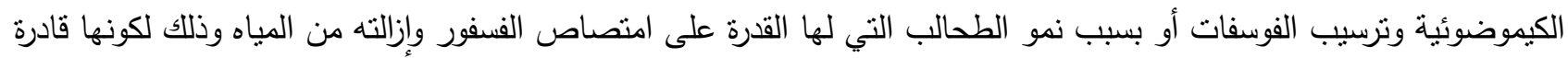
على الاستفادة من الفوسفات المتوافر في المياه لأجل نشاطاتها الفسيولوجية (Hu et al., 2010). 
الجدول 7: معدل نتائج ايونات الفوسفات (ملفم/تتر) خلال مدة المعالجة الطبيعية

\begin{tabular}{|c|c|c|c|c|c|c|c|}
\hline الإزالةة \% & أسابيع من أربعة & أسابيع من ثلاثة & بعد أسبوع من & من المعالجة أريعة أيام & مند يوم & قالجة & المعاملات \\
\hline$\% 97$ & 0.13 & 1.40 & 4.34 & 3.71 & 5.06 & 6.01 & $\mathrm{t}_{1}$ \\
\hline$\% 98$ & 0.10 & 0.12 & 4.71 & 3.60 & 4.62 & & $\mathrm{t}_{2}$ \\
\hline$\% 98$ & 0.10 & 0.12 & 4.62 & 3.37 & 4.66 & & $t_{3}$ \\
\hline$\% 98$ & 0.12 & 0.11 & 4.43 & 3.45 & 4.50 & & $\mathrm{t}_{4}$ \\
\hline
\end{tabular}

وقد تمت ملاحظة انخفاض كبير في العدد الكلي للبكتريا وبكتريا القولون البرازية أثناء عمليات المعالجة الطبيعية كما هو

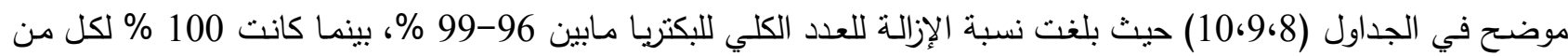
بكتريا القولون البرازية وبكتريا E. coli بعد مرور أربعة أيام من المعالجة ولكل المعاملات مقارنة بأعدادها قبل المعالجة، وهذه



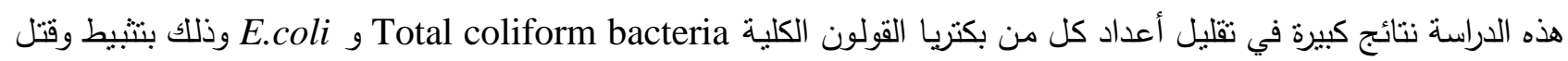
البكتربا إذ بلغت نسبة الإزالة الى 52\% بعد مرور يوم واحد من التعريض لأشعة الثمس وزادت هذه النسبة في اليوم الثاني لتصل الى 100\%.

الجدول 8: معدل نتائج العدد الكلي للبكتريا (خلية/مل) خلال مدة المعالجة الطبيعية

\begin{tabular}{|c|c|c|c|c|c|c|c|}
\hline الإزالةة & أسبابيع من أريعة & أسبابيع من & بعد أسبوع من & بعد أريعة أيام من & بعد يوم من & المعالجة & المعاملات \\
\hline$\% 100$ & N.D & N.D & N.D & $10^{5} \times 4$ & $10^{5} \times 18$ & $10^{7} \times 1$ & $t_{1}$ \\
\hline$\% 100$ & N.D & N.D & N.D & N.D & $10^{6} \times 12$ & & $t_{2}$ \\
\hline$\% 100$ & N.D & N.D & - & $10^{5} \times 2$ & $10^{6} \times 9$ & & $t_{3}$ \\
\hline$\% 100$ & N.D & N.D & N.D & $10^{5} \times 1$ & $10^{6} \times 6$ & & $\mathrm{t}_{4}$ \\
\hline
\end{tabular}


تتقية مياه الصرف الصحي بالتعريض.

الجدول 9: معدل نتائج اعداد بكتريا القولون البرازية (خلية/100مل) خلال مدة المعالجة الطبيعية

\begin{tabular}{|c|c|c|c|c|c|c|c|}
\hline الإزالةة & أسابيع من أربعة & أسابيع من & من المعالجة أسبوع & من المعالجة أربعة أيام & بعد يوم من & قالمعالجة & المعاملات \\
\hline$\% 100$ & N.D & N.D & N.D & N.D & $10^{3} \times 150$ & $10^{5} \times 4$ & $t_{1}$ \\
\hline$\% 100$ & N.D & N.D & N.D & N.D & $10^{3} \times 93$ & & $\mathrm{t}_{2}$ \\
\hline$\% 100$ & N.D & N.D & N.D & N.D & $10^{3} \times 460$ & & $t_{3}$ \\
\hline$\% 100$ & N.D & N.D & N.D & N.D & $10^{3} \times 240$ & & $t_{4}$ \\
\hline
\end{tabular}

الجدول 10: معدل نتائج أعداد بكتريا E. coli (خلية/100مل) خلال مدة المعالجة الطبيعية

\begin{tabular}{|c|c|c|c|c|c|c|c|}
\hline الإزالة\% & بعد أريعة أسابيع & أسعد ثلاثة & بعد أسبوع & بعد أربعة أيام & بعد يوم من & قالجبل & المعاملات \\
\hline$\% 100$ & N.D & N.D & N.D & N.D & $10^{3} \times 150$ & $10^{5} \times 4$ & $\mathrm{t}_{1}$ \\
\hline$\% 100$ & N.D & N.D & N.D & N.D & $10^{3} \times 93$ & & $t_{2}$ \\
\hline$\% 100$ & N.D & N.D & N.D & N.D & $10^{3} \times 460$ & & $t_{3}$ \\
\hline$\% 100$ & N.D & N.D & N.D & N.D & $10^{3} \times 240$ & & $\mathrm{t}_{4}$ \\
\hline
\end{tabular}

N.D : غير محسوس.

كذلك أثشارت نتائج دراسة (Olutiola et al., 2010) الى أن نسبة الإزالة في برك أكسدة مياه الصرف الصحي بلغت (53)\% للعدد الكلي للبكتريا و (85)\% للعدد الكلي لبكتريا القولون.

برهنت الأشعة الثمسية على قدرتها على القضاء على الكائنات المسببة للأمراض مع تقليل كمية المواد العضوية في المياه

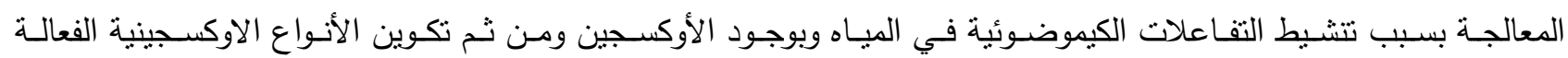
(ROS) Reactive Oxygen Species

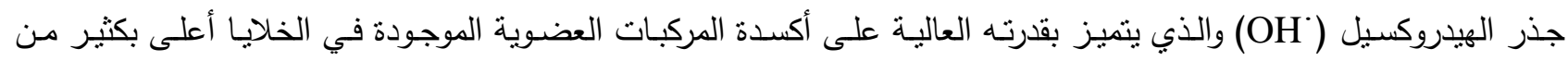

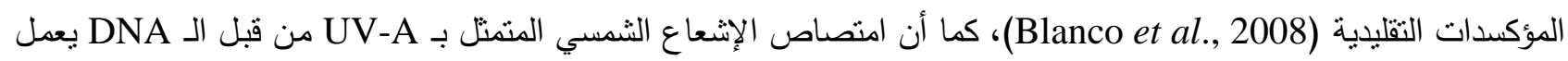
على تكوين thymine dimers الذي يؤدي بدوره الى عرقلة تضاعف الـ Oates et al., 2003) DNA). كذلك فان رفع درجة الحرارة سيزيد من عمليات قتل البكتريا بسبب حصول تآزر بين الإثعاع والحرارة (Blanco et al., 2008) إذ أن الحرارة المتولدة

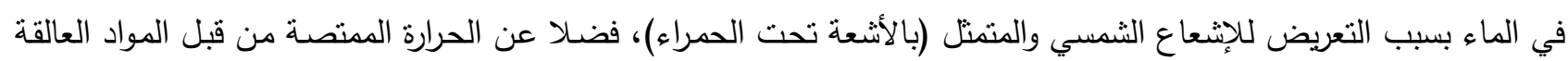

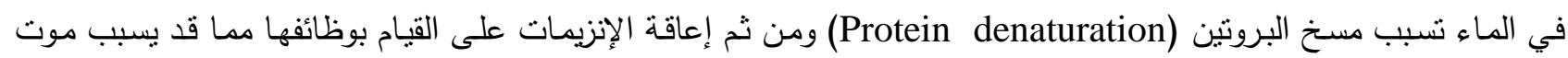
الخلية (Brock et al., 2002)، وتشير الأبحاث والدراسات الى وجود علاقة أو نرابط مابين التعرض لأشعة الثمس ودرجات الحرارة ونشاطات عملية البناء الضوئي وانخفاض أعداد بكتريا الكوليفورم، حيث يؤدي pH والأوكسجين دورا في التأثير في تركيز 
بكتريا الكوليفورم (Moreira et al., 2009)، وهذا ما أكده (Yeh et al., 2011) عند دراسته لنمو الطحالب في الأنظمة المائية، إذ أدى ارتفاع الـ pH الى 9 الى حدوث انخفاض معنوي في أعداد بكتريا الكوليفورم، إذ بسبب الـ pH القاعدي تنأين

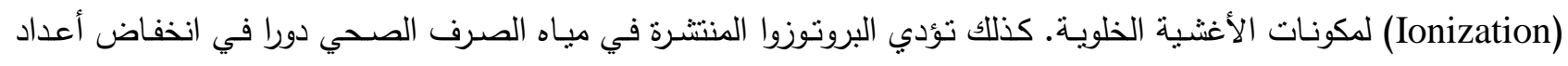
البكتريا من خلال استهلاكها للبكتريا الموجودة في المياه وتغذيتها على جزيئات المواد العضوية (Ostroumov, 2006)، كذللك


و Candida albicans و و و و Calmonella typhimurium cholera

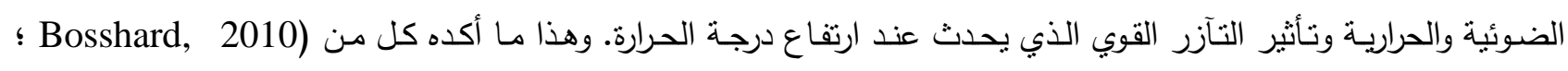
(McGuigana et al., 2012 الأنظمة الإنزيمية نتيجة لاكسدة الحوامض الامينية في البروتينات والحوامض الدهنية المتعددة غير المشبعة في اللبييدات.

\section{الاستتتاجات}

1- أظهرت المعالجة باستخدام الإثعاع الثمسي كفاءة عالية في إزالة العديد من الملوثات والقضاء على نسبة كبيرة من أعداد أدلة التلوث البكتيري.

2- لوحظ تحسن كبير في شفافية المياه المعالجة بالإشعاع الثمسي واختفاء الرائحة الكريهة نتيجة لتوفير الظروف الهوائية من قبل الطحالب.

\section{التوصيات}

1- الوعي البيئي ومنع حدوث التجاوزات بتصريف المياه الثقبلة مـع مياه المجاري المصرفة الى النهر ، مـع إجراء الفحوصـات الدورية والمستمرة على نوعية مياه الفضلات المطروحة.

2- نقل مياه المجاري الى المنخفضات جنوب مدينة الموصل لغرض تعريضـها الى عمليات المعالجة الطبيعية ومن ثم تحسين نوعية هذه المياه للاستخدامات الزراعية والحد من ضغوط التلوث على نوعية مياه نهر دجلة.

\section{المصادر العربية}

ألثاهري، يوسف جبار ؛ إسماعيل، محمد بشير ؛ الصوفي، بلقيس يحيى (2009). تأثير الإضـاءة وتركيز النتروجين والفسفور على لئ

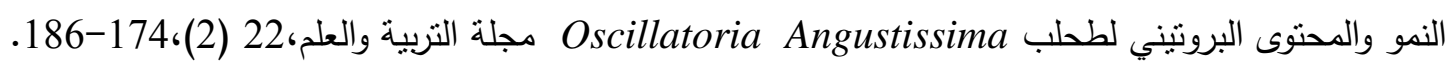
الصفاوي، عبدالعزيز يونس؛ البرواري، مشير رشيد؛ خدر ، نوزت خلف (2009). دراسة الخصائص الطبيعية والكيميائية والبايولوجية

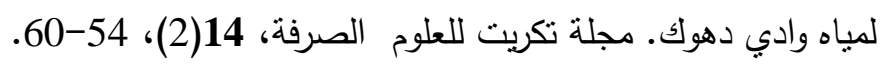
الصفاوي، عبدالعزيز يونس طليع؛ السردار، نور ميسر (2013)، استخدام بعض الطرائق الفيزياوية الحيوية لتحسين نوعية مياه الآبار ، مقبول للنشر في مجلة التربية والعلم.

الصفاوي، عبدالعزيز يونس طليع؛ الطائي، نور ضياء صالح (2013). دراسة بيئية وبكتريولوجية للفضلات السائلة من مستشفيات

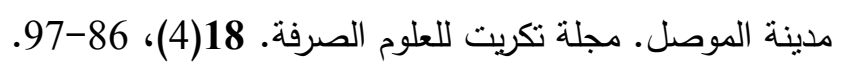
الصفاوي، عبدالعزيز يونس طليع؛ السنجري، وفاء عصام (2013). النتقية الذاتية لمياه وادي الخرازي في مدينة الموصل. مقبول للنشر في مجلة التربية والعلم.

الصفاوي، عبدالعزيز يونس طليع؛ العساف، أزهار يونس (2013). دراسـة بيئية وبيولوجيـة للفضـلات السائلة في وادي الدانفيلي وتأثيره على مياه نهر دجلة جنوب مدينة. 


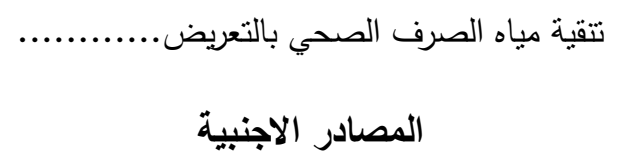

APHA; AWWA ; WCPE. (1998). "Standard Method for Examination of Water and Wastewater". 20 ed., Washington, DC, USA.

Blanco, J.; Malato, S.; Fernandez, P.; Alarcon, D.; Gernjak, W.; Maldonado, M.I. (2008). "Solar Energy and Feasible Applications to Water Processes". 5 ${ }^{\text {th }}$ European Thermal. Sciences Conference, the Netherlands.

Bosshard, F.; Riedel, K.; Schneider, T.; Geiser, C.; Bucheli, M.; Egli, T. (2010). Protein oxidation and aggregation in UVA-irradiated $E$. coli cells as signs of accelerated cellular senescence. Env. Microbi, 12, $2931-2945$.

Brock, T.; Madigan, T.; Martinko, J.; Parker, J. (2002). Biology of microorganisms englewood cliffs, NJ: Prentice Hall. In: Oates, P.M.; Shanahan, P.; Polz, M.F. (2003). "Solar Disinfection (SODIS) simulation of solar radiation for global assessment and application for point-of-use water treatment in Haiti". Water Res. 37,47-54.

Heidenwag, I.; Langheinrich, U.; Luditz, V. (2001). Self purification in upland and lowland streams. Acta hydrochim. Hydrobio, 29 (1), 22-33.

Hu, Y.; Wang, S.; Wang, C.; Jiang, H. (2010)."Characterization of Phosphorus Removal in the Rivers Inputting in to Lake Taihu". $4^{\text {th }}$ International Conference on Bioinformatics and Biomedical Engineering. 18-20, China.

Hussein, F.H.; Abass, T.A. (2010). Solar photolysis and photocatalytic Treatment of textile industrial wastewater. Int. J. Chem.Sci., 8(3), 1409-1420.

Ifabiyi, I.P. (2008). Self Purification of a freshwater Stream in Ile-Ife Lesson for water management. J. Hum. Ecol., 24(2), 131-137.

Kumar, A.; Bisht, B.S., Joshi, V.D.; Dhewa, T. (2011). Review on bioremediation of polluted environment: a management tool. inter. J. Envi. Sci. 1(6).

Lou, J.; Huang, C.; Han, J.; Huang, Y. (2010). Generation of disinfection by-product (DBPs) at two advanced water treatment plants. Envir. Mon. Assess. 162, 365-375.

Malaah, W.N. (2013). Study the effect of the medical city wastewater on the water Quality of Tigris River at Baghdad City. Msc. Thesis. College of Science. University of Baghdad. Iraq.

Manhan, S.E. (2004)." Environmental Chemistry". $8^{\text {th }}$ ed. Crc press. Washington, DC.USA 781p.

McGuigana, K.G.; Conroya, R.M.; Moslerb, H.J.; Du Preezc, M.; Jaswac, E.U.; Ibanezd, P.F. (2012). Solar water disinfection: A review from bench-top to roof-top. J. Hazard. Materials .In press.

McGuigana, K.G.; Joyce, T.M.; Onroy, R.M.; Gillespie, J.B.; Elmore-Meegan, M. (2012). Solar disinfection of drinking water contained in plastic bottles: characterizing the bacterial inactivation process. J. Appl. Microbi. 84(6). In: Oates, P.M.; Shanahan, P.; Polz, M.F. (2003). Solar Disinfection (SODIS) simulation of solar radiation for global assessment and application for point-of-use water treatment in Haiti. Water Res., 37, 47-54.

Moreira, J.F.; Cabral, A.R.; Oliveira, R.; Silva, S.A. (2009). Causal model to describe the variation of faecal coliform concentrations in a pilot - scale test consisting of Ponds aligned in series. Ecolog. Engin., 35, 791-799.

Nogueira, K.R.B.; Teixeira, A.C.S.; Nascimente, C.A.; Guardani, R. (2008). Use of solar energy in the treatment of water contaminated with phenol by Photochemical processes. Brazil. J. Che. Eng. 25(4), 671-682.

Oates, P.M.; Shanahan, P.; Polz, M.F. (2003). Solar disinfection (SODIS) simulation of solar radiation for global assessment and application for point-of-use water treatment in Haiti. Water Res., 37, 47-54.

Olutiola, P.O.; Awojobi, K.O.; Oyedeji, O.; Ayansina, A.D.; Cole, O.O. (2010). Relationship between bacterial density and chemical composition of a tropical sewage oxidation pond. Afri. J. Envi. Sci. and Tech., 4(9), 595-602. 


$$
\text { عبد العزيز يونس طليع الصفاوي و ريم أياد طلعت }
$$

Ostroumov, S.A. (2006). Biomachinery for maintaining water quality and natural water Selfpurification in marine and estuarine systems: elements of a qualitative theory. Int. J. oceans and Oceanog., 1(1), 111-118.

Schertenleib, R.; Wegelin, M. (2002). Solar water disinfection a guide for the application of SODIS. Swiss Federal Institute of Environmental Science and Technology (EAWAG) and Department of Water and Sanitation in Developing Countries (SANDEC).

Vidali, M. (2001). Bioremediation an overview. Pure Appl. Chem., 73(7), 1163-1172. In: Kumar, A, Bisht, B.S., Joshi, V.D.; Dhewa, T. (2011)."Review on Bioremediation of Polluted Environment: A management Tool". Int. J. Env. Sci., 1(6).

WHO, (2003). Algae and cyanobacteria in fresh water, in Guidelines for safe Recreational water Environments (1): Coastal and fresh water, World Health Organization, Geneva.

Yeh, T.Y.; Ke, T.Y; Lin, Y.L. (2011). Algal growth control within natural water purification system: Macrophyte light Shading Effects. Wat. Air and Soil Pollut., 214, 575-586. 